\title{
Experimental and Theoretical Investigations of a Novel Multi-Stage Direct Contact Membrane Distillation Module
}

\author{
Young-Deuk Kim, Woo-Seung Kim* \\ Department of Mechanical Engineering, Hanyang University \\ 55 Hanyangdaehak-ro, Sangnok-gu, Ansan, Gyeonggi-do 15588, Republic of Korea \\ youngdeuk@hanyang.ac.kr; *wskim@hanyang.ac.kr
}

\begin{abstract}
Global climate change and variability have a negative impact on a water supply and quality in remote areas by reducing water availability and contaminant dilution. This will continue to be exacerbated by limited and inadequate water supply, insufficient water treatment and low infrastructure. Thus, an economic desalination system with a small scale and footprint for such regions is strongly demanded in the desalination markets. Here, a direct contact membrane distillation (DCMD) process has the simplest configuration and potentially the highest permeate flux among all the possible MD processes. And it also can be consisted easily by a multi-stage manner to achieving an enhancement of compactness, productivity, versatility and cost-effectiveness. In this study, therefore, an innovative multistage direct contact membrane distillation module under countercurrent-flow operation is first designed and both theoretically and experimentally investigated to identify the feasibility and operability of its design for the desalination. For a three-stage DCMD module with a membrane area of $0.01 \mathrm{~m}^{2}$ at each stage, the daily water production is found to be $21.5 \mathrm{~kg}$ at the inlet feed and permeate flow rates of $1.5 \mathrm{l} / \mathrm{min}$ and the inlet feed and permeate temperature of $70^{\circ} \mathrm{C}$ and $25^{\circ} \mathrm{C}$.
\end{abstract}

Keywords: multi-stage DCMD; module design; desalination; composite membrane; experiment; modeling

\section{Introduction}

A multi-stage MD process with different configurations such as series, parallel and series/parallel arrangement of MD modules has been studied to efficiently increase water production and system performance [1,2]. It has been shown that the multi-stage concept for air gap membrane distillation (AGMD) and vacuum membrane distillation (VMD) processes could reduce energy consumption by recovering the latent heat of water vapor condensation $[3,4]$. By applying the multi-stage scheme, an improvement of MD permeate flux can be achieved with thermal entrance effects, which affects the enhancement of heat transfer coefficient near the inlet flow region of each stage as the thermal boundary layer begins to develop near the inlet region [5,6]. In addition, due to the separated module configuration, the multi-stage scheme may provide supplementary advantages, such as easy to maintenance, replacement and check for the leaks in the module [2]. Such a multi-stage MD system has been studied by many researchers [2,4,7-9]. Lee and Kim [2] presented various configurations of multi-stage VMD systems. Among the proposed systems which have various configuration manners, an optimized multi-stage VMD system configuration was determined by cost evaluation. Kim et al. [7] proposed a solar-assisted multi-stage VMD system with heat recovery unit, which could increase the thermal efficiency and water production. Blanco Gálvez et al. [9] reported an innovative solar-powered AGMD desalination system. The solar powered multi-stage AGMD system was developed and experimentally examined to improve the energy efficiency and reduce the water production cost. Also, the memsys had commercialized a vacuum-multi effect membrane distillation (V-MEMD) module, which achieved highly efficient heat recovery as compared to conventional thermal desalination processes. The solar driven memsys system showed good operating performance with a flux at approximately $7 \mathrm{~L} / \mathrm{m}^{2} \mathrm{~h}$ on a sunny day with a seawater feed [4].

All of the aforementioned researches have been made an effort to develop a commercialized MD system using a multistage concept due to negligible conductive heat loss through the membrane of both AGMD and VMD processes. However, the AGMD has several drawbacks such as complex module design and low permeate flux and the VMD also has several disadvantages such as treatment of non-condensable gases, requirement of additional vacuum pump and membrane pore wetting which easily occurs by vacuuming the permeate side of the membrane. On the other hand, a direct contact membrane distillation (DCMD) process has the simplest configuration and potentially the highest permeate flux among all the possible MD processes. In addition, the effect of diffusion of non-condensable gases on the permeate flux is negligible in DCMD 
process due to its very small quantity compared with a high DCMD permeate flux [10]. Furthermore, DCMD can be configured easily with a multi-stage manner to achieving an improvement of compactness, cost-effectiveness, productivity and versatility.

The ultimate objective of this work is to develop a high-performance multi-stage direct contact membrane distillation (MDCMD) process that is applicable to a small scale and footprint desalination system. In this study, therefore, an innovative MDCMD module under countercurrent-flow operation has been first designed and both theoretically and experimentally examined to demonstrate the feasibility and operability of module design for the desalination. A rigorous numerical model, which was developed in our previous work [11], has been modified to incorporate a thermal entrance effect near the inlet flow region of each stage for the performance prediction of MDCMD process. Further investigations have been conducted to identify the effect of the number of module stages on the mean permeate flux, performance ratio and daily water production of the MDCMD system.

\section{Experimental}

As shown in the SEM images (clockwise from top left: 100x, 500x, 1,000x and 10,000x magnifications) in Fig. 1 [11], a commercial hydrophobic microporous PTFE/PP composite membrane has been used for this study. It appears that the knotfibril net structured PTFE active layer (dark gray in top right of Fig. 1) is partially covered by the PP scrim support layer (white gray). Here, the PTFE active layer not covered by the PP support layer at the permeate side indicates an effective area for diffusion, which can be expressed by the surface porosity defined as the surface area of PTFE active layer exposed to the permeate side divided by the total membrane surface area. The surface porosity is found to be $42 \%$ using the CAD software based on the SEM images.

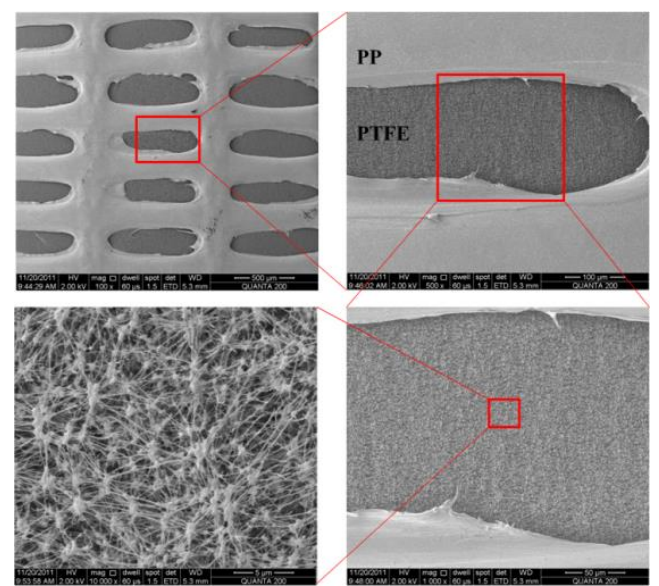

Fig. 1: SEM images of a commercial PTFE/PP composite membrane. Clockwise from top left: 100x, 500x, 1,000x and 10,000x magnifications [11].

Fig. 2 represents a schematic (Fig. 2a) and picture (Fig. 2b) of the novel MDCMD module made of polycarbonate material. The module consists of two exterior units and a couple of interior units. The number of interior units depends on the number of stages in more than single stage, i.e., the number of interior units equal to the number of stages minus 1 , while in the case of single stage the interior unit is not required. As shown in this figure, the rotation coupling implementation is employed to assemble the adjacent units. Here, the module requires no external pipelines between the stages, by incorporating internal flow channels with a first-in-last-out (FILO) configuration, which helps form a uniform flow in a channel width direction, resulting in an improvement of the MD performance. Such multi-stage module concept can achieve an enhancement of compactness, productivity, versatility and cost-effectiveness in the DCMD process. Specifications of MDCMD module include $0.01 \mathrm{~m}^{2}(0.1 \mathrm{~m} \times 0.1 \mathrm{~m})$ effective membrane area in each stage and $3 \mathrm{~mm}$ channel height in both feed and permeate sides. As a membrane support and turbulence promoter, polypropylene (PP) mesh spacers have been implemented in both feed and permeate channels. 


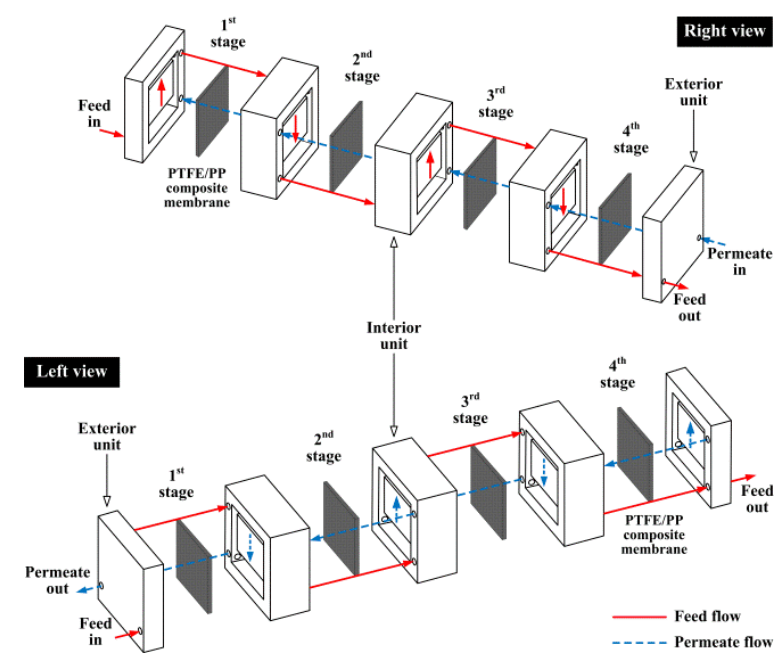

(a)
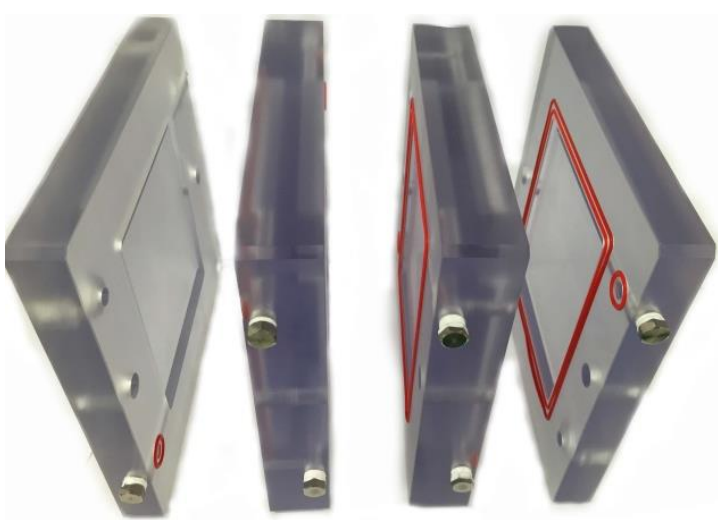

(b)

Fig. 2: (a) Schematic and (b) picture of the MDCMD module with four and three stages, respectively.

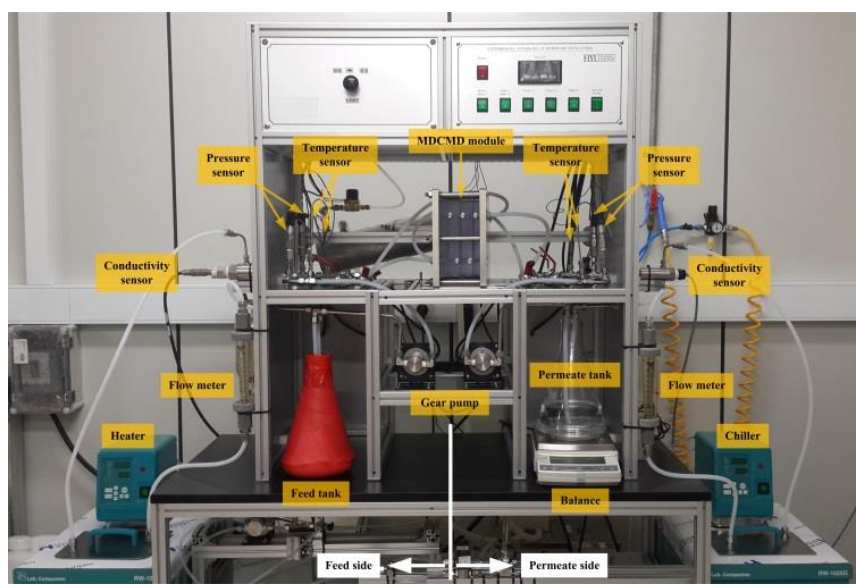

Fig. 3: Picture of the experimental set-up.

A picture of experimental set-up is shown in Fig. 3. Deionized (DI) and tap waters are used as bulk permeate and feed solutions, respectively. The tap water flows through the active layer side of the membrane, while DI water is circulated through the support layer side of the membrane in a countercurrent flow manner. Feed and permeate temperatures are kept constant by using a heater and chiller (RW-1025G, Lab Companion), respectively. The permeate production rate is measured using an electronic balance (CUX-6200H, CAS). Temperature, pressure and volume flow rate at both inlet and outlet of the module are simultaneously monitored at both feed and permeate sides. In order to detect the leaks or pore wetting of the membrane, the conductivity of feed and permeate solutions at the outlet of module is measured by a conductivity/resistivity sensor, and a corresponding signal is transmitted to a PC via a transmitter (M300, Mettler-Toledo Thornton) and a data acquisition device. The performance of MDCMD system using a composite PTFE/PP membrane has been investigated by varying the inlet feed temperature in the range of $50{ }^{\circ} \mathrm{C}-70{ }^{\circ} \mathrm{C}$ and the number of stages from 1 to 3 while keeping inlet permeate temperature constant at $25^{\circ} \mathrm{C}$. The inlet feed and permeate volume flow rates in the range of $1.01 / \mathrm{min}$ to $2.51 / \mathrm{min}$ are tested for single-stage module and for two- and three-stage modules its values are $1.0 \mathrm{l} / \mathrm{min}$ and $1.5 \mathrm{l} / \mathrm{min}$ due to a lack of heating and cooling capacities. For reproducibility, all experiments are conducted more than three times and the maximum deviation in the measured permeate fluxes is found to be less than $\pm 6 \%$.

\section{Theoretical Approach}

To demonstrate the feasibility and operability of MDCMD module designed in the present work, a theoretical investigation has been also performed. As shown in Fig. 4a, the heat and mass transfers occur simultaneously across the 
boundary layers near the membrane surfaces and through the PTFE/PP composite membrane. Also, the presence of turbulence or eddy currents induced by the spacers in both channels will yield better flow characteristics. As a result, the thickness of thermal boundary layer in the spacer-filled channel is less than that in the empty channel, which yields the membrane surface temperatures to be closer to bulk temperatures. Thus, temperature polarization can be reduced, and permeate fluxes can be enhanced due to larger vapor pressure difference through the PTFE/PP composite membrane. Detailed theoretical models and solution procedure for the heat and mass transfer through the composite membrane and transport phenomena on the bulk feed and permeate flows have already been demonstrated in our previous work [11].

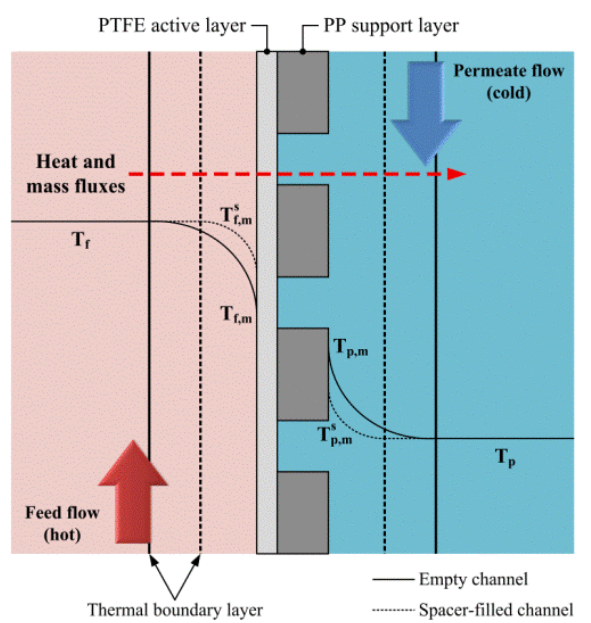

(a)

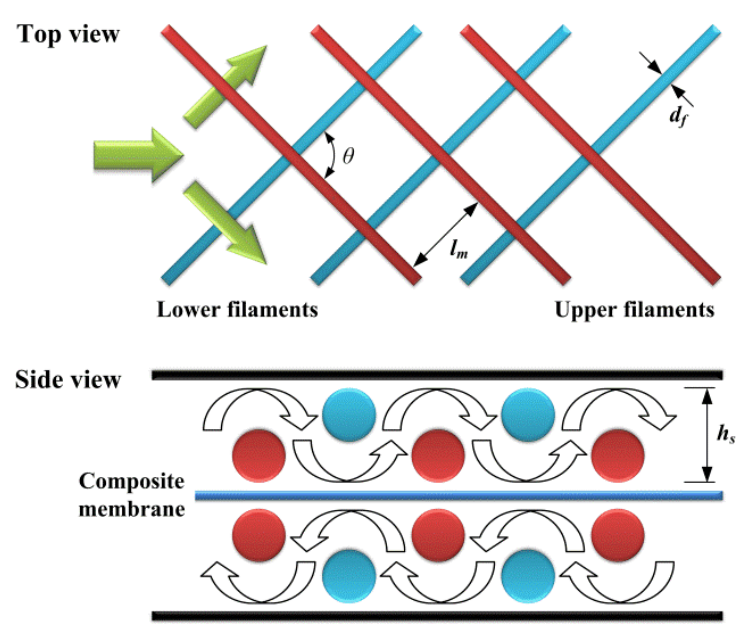

(b)

Fig. 4: (a) Schematic diagram of temperature polarization in both empty and spacer-filled channels and (b) geometric characteristics of a non-woven net spacer and flow pattern in spacer-filled channel.

In the present work, the theoretical model developed previously has been modified to incorporate the thermal entrance effect at each stage as a consequence of the adoption of multi-stage concept. In order to estimate the heat transfer coefficient $h$ in both spacer-filled feed and permeate channels, therefore, the modified Dittus-Boelter's correlation on a flat surface of fully developed turbulent flow has been employed as follows [5,11,12-14]:

$$
N u=\frac{h d_{h}}{k}=k_{s p} 0.023\left(1+6 d_{h} / L\right) \operatorname{Re}^{0.8} \operatorname{Pr}^{0.33}
$$

With $\operatorname{Re}=\rho v d_{h} / \mu, \operatorname{Pr}=\mu c_{p} / k$ and $d_{h}=\frac{4 \varepsilon_{s p}}{2\left(w_{c}+h_{c}\right) / w_{c} h_{c}+4\left(1-\varepsilon_{s p}\right) / d_{f}}$ for a spacer-filled channel, where $k_{s p}$ is the spacer factor, $d_{h}$ is the channel hydraulic diameter, $k$ is the thermal conductivity of the bulk feed or permeate, $L$ is the effective membrane length, $\varepsilon_{s p}$ is the spacer porosity, $w_{c}$ is the channel width, $h_{c}$ is the channel height and $d_{f}$ is the diameter of spacer filament.

As can be expected from the spacer factor included in Eq. (1), the spacer can be employed as a membrane support and turbulence promoter, resulting in an enhancement of heat and mass transfers and flow resistance [5,11,15]. As illustrated in Fig. 4b, the main geometric parameters of the spacer factor are; i) a hydrodynamic angle (in degree, $\theta$ ), ii) a mesh size $\left(l_{m}\right)$, iii) a filament diameter $\left(d_{f}\right)$, iv) a spacer thickness $\left(h_{s}\right)$ and $(\mathrm{v})$ a spacer porosity $\left(\varepsilon_{s p}\right)$ which can be estimated from aforementioned four geometric parameters as follows $[11,15]$ :

$$
\varepsilon_{s p}=1-\frac{\pi d_{h}^{2}}{2 l_{m} h_{s} \sin \theta}
$$

In this study, therefore, the spacer factor correlation can be defined as follows: 


$$
k_{s p}=c_{1}\left(\frac{d_{f}}{h_{s}}\right)^{c_{2}}\left[\sin \left(\frac{\theta}{2}\right)\right]^{c_{3}} \exp \left[c_{4}\left|\ln \left(\varepsilon_{s p}\right)\right|^{c_{5}}\right]
$$

Five parameters $\left(c_{1}, c_{2}, c_{3}, c_{4}, c_{5}\right)$ in the spacer factor above are fitted to the experimental permeate flux data by using a conjugate gradient method (CGM) [16]. The coefficient of determination $R^{2}$, which indicates the percentage of variability in the dependent variables (the variance about the mean), is implemneted to analyze the fitting degree of spacer factor with the measured data and expressed as:

$$
R^{2}=1-\frac{\sum_{i=1}^{N}\left(J_{m, \exp , i}-J_{m, \operatorname{sim}, i}\right)^{2}}{\sum_{i=1}^{N}\left(J_{m, \exp , i}-\bar{J}_{m, \operatorname{sim}, i}\right)^{2}}
$$

with $\bar{J}_{m, \exp }=\frac{1}{N} \sum_{i=1}^{N} J_{m, e x p, i}$

where $J_{m, e x p}$ and $J_{m, s i m}$ are the mean value of measured and predicted permeate fluxes, respectively, and $N$ is the number of measured permeate flux data.

For the performance investigation of MDMCD process using a multi-stage concept, the mean performance ratio $(P R)$ are expressed as [11]

$$
P R=\frac{1}{L} \int_{0}^{L} \eta_{z} d z
$$

where $\eta_{z}$ is the local performance ratio, determined as the ratio of the vaporization heat associated with the permeate flux to the heat transferred through the membrane, and given by [11]

$$
\eta_{z}=\frac{\left.\varepsilon J_{z} \Delta H\right|_{a l}+\left.(1-\epsilon) J_{z} \Delta H\right|_{a l-s l}}{Q_{m}}
$$

where $\varepsilon$ is the surface porosity of composite membrane mentioned in the first paragraph of Section $2, J_{z}$ is the local permeate flux, $\left.\Delta H\right|_{a l}$ and $\left.\Delta H\right|_{a l-s l}$ are the enthalpy of evaporation at the mean temperature through the active layer membrane and the active/support layer membrane, respectively, and $Q_{m}$ is the heat flux through the membrane.

\section{Results and Discussion}

In order to identify the feasibility and operability of multi-stage module design with a countercurrent-flow configuration developed in the present work, experimental and theoretical investigations on its performance have been carried out by varying an inlet feed temperature in the range of $50{ }^{\circ} \mathrm{C}-70{ }^{\circ} \mathrm{C}$ at the inlet permeate temperature of $25^{\circ} \mathrm{C}$ and the feed and permeate volume flow rates in the range of $1.0 \mathrm{l} / \mathrm{min}-1.5 \mathrm{l} / \mathrm{min}$.

With an increase in the inlet feed temperature from $50{ }^{\circ} \mathrm{C}$ to $70{ }^{\circ} \mathrm{C}$ at the both stream flow rates of $1.01 / \mathrm{min}$ for singlestage module, the measured mean permeate flux increases from $11.9 \mathrm{~kg} / \mathrm{m}^{2} \mathrm{~h}$ to $31.2 \mathrm{~kg} / \mathrm{m}^{2} \mathrm{~h}$, whereas the model prediction shows the increase of mean permeate flux from $10.9 \mathrm{~kg} / \mathrm{m}^{2} \mathrm{~h}$ to $29.1 \mathrm{~kg} / \mathrm{m}^{2} \mathrm{~h}$. The mean performance ratio increases asymptotically from $62.2 \%$ to $80.7 \%$ (black lines in Fig. 5a). It is shown that, at the both stream flow rates of $1.51 / \mathrm{min}$, the measured mean permeate flux increases from $14.1 \mathrm{~kg} / \mathrm{m}^{2} \mathrm{~h}$ to $37.7 \mathrm{~kg} / \mathrm{m}^{2} \mathrm{~h}$ and the model-based permeate flux increases from $13.8 \mathrm{~kg} / \mathrm{m}^{2} \mathrm{~h}$ to $37.7 \mathrm{~kg} / \mathrm{m}^{2} \mathrm{~h}$. Also, the mean performance ratio increases gradually from $62.8 \%$ to $81.3 \%$ (red lines in Fig. 5a). A good agreement between the measured and predicted data is observed, i.e., maximum relative deviations of $8.4 \%$ for $1.0 \mathrm{l} / \mathrm{min}$ and $3.5 \%$ for $1.5 \mathrm{l} / \mathrm{min}$. It is noted that a higher permeate flux is achieved at a higher feed temperature as the partial vapor pressure increases exponentially with a temperature. Furthermore, a higher flow rate provides an enhanced heat transfer through both feed and permeate boundary layers and then reduces the temperature polarization, which indicates a higher transmembrane temperature difference resulting in a higher permeate flux in DCMD process [3,17-21]. 


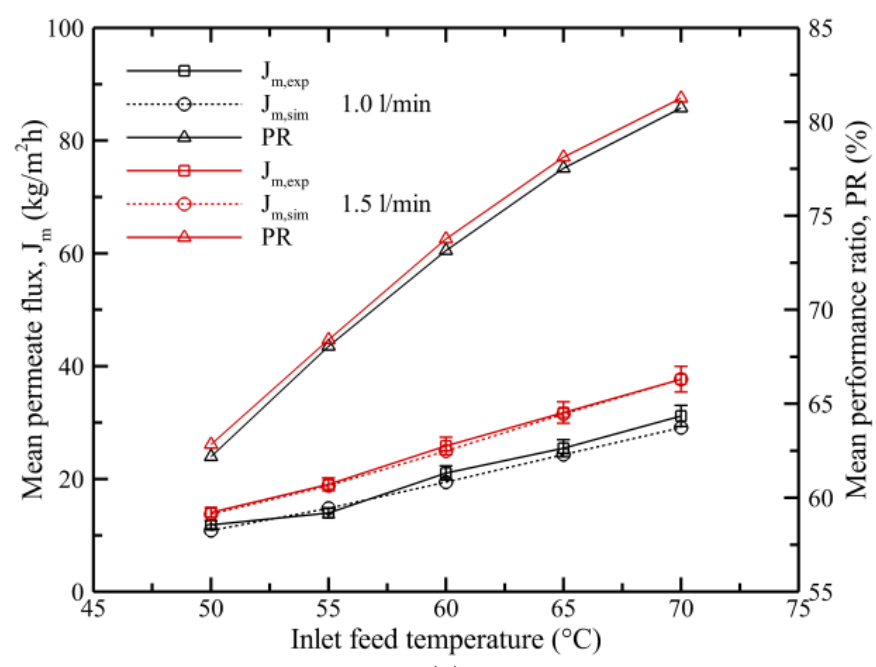

(a)

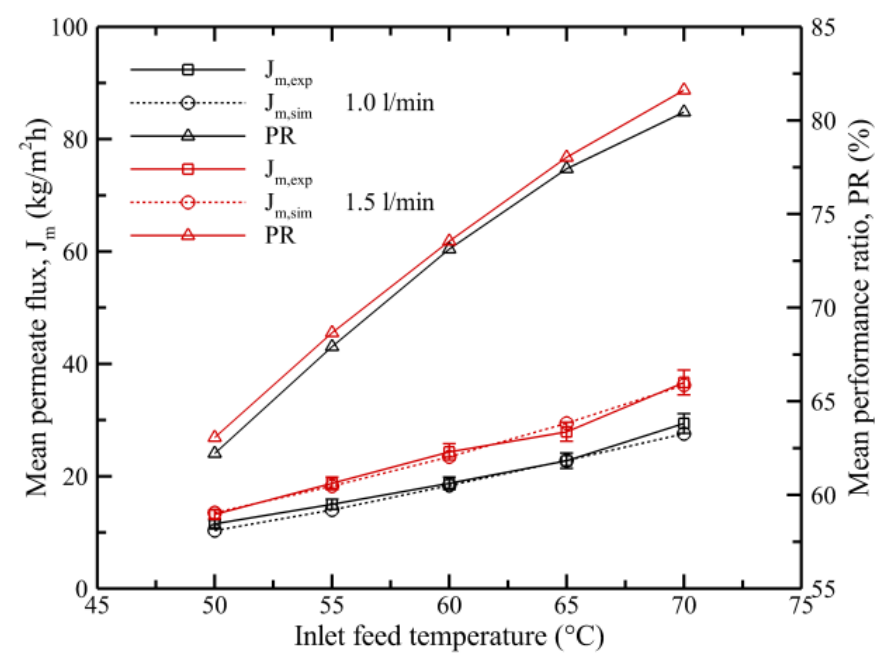

(b)

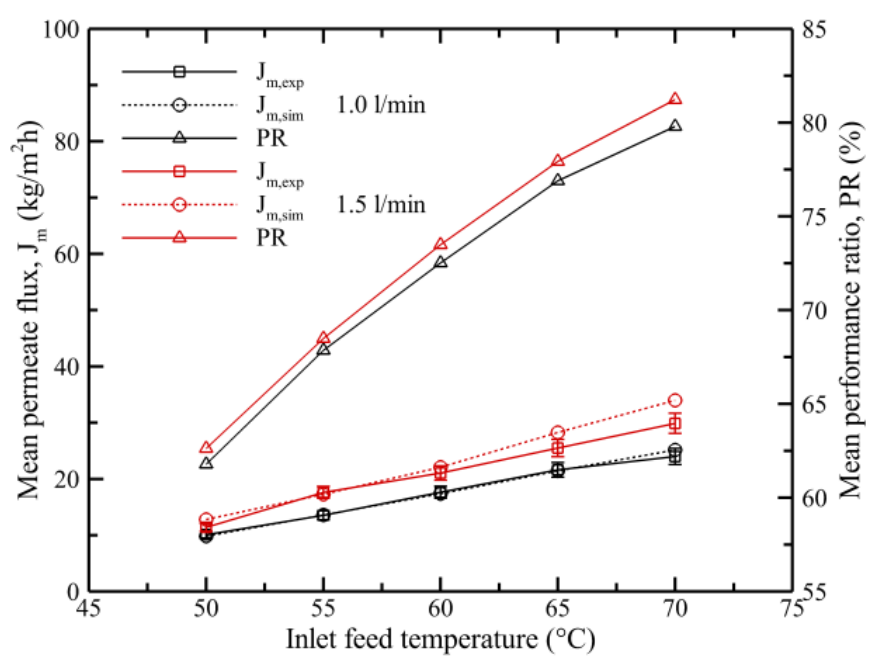

(c)

Fig. 5: Effect of inlet feed temperature and flow rate (1.0 1/min and $1.51 / \mathrm{min}$ ) on the mean permeate flux (measured and predicted) and performance ratio (predicted) of (a) single-, (b) two- and (c) three-stage modules.

For the two-stage DCMD module at the both stream flow rates of $1.0 \mathrm{l} / \mathrm{min}$ (black lines in Fig. $5 \mathrm{~b}$ ), the measured mean permeate flux increases from $11.5 \mathrm{~kg} / \mathrm{m}^{2} \mathrm{~h}$ to $29.4 \mathrm{~kg} / \mathrm{m}^{2} \mathrm{~h}$, whereas and the predicted mean permeate flux increases from 10.4 $\mathrm{kg} / \mathrm{m}^{2} \mathrm{~h}$ to $27.6 \mathrm{~kg} / \mathrm{m}^{2} \mathrm{~h}$, with an increase in the inlet feed temperature from $50{ }^{\circ} \mathrm{C}$ to $70{ }^{\circ} \mathrm{C}$. The mean performance ratio increases from $62.2 \%$ to $80.5 \%$. At the inlet feed and permeate flow rates of $1.5 \mathrm{l} / \mathrm{min}$ (red lines in Fig. $5 \mathrm{~b}$ ), the measured mean permeate flux increases from $13.2 \mathrm{~kg} / \mathrm{m}^{2} \mathrm{~h}$ to $36.7 \mathrm{~kg} / \mathrm{m}^{2} \mathrm{~h}$ and the model-based permeate flux increases from 13.5 $\mathrm{kg} / \mathrm{m}^{2} \mathrm{~h}$ to $36.2 \mathrm{~kg} / \mathrm{m}^{2} \mathrm{~h}$. Also, the performance ratio increases gradually from $63.1 \%$ to $81.6 \%$. The model predictions on the permeate flux are also in good accordance with the measured results, i.e., maximum deviations of $10.2 \%$ and $5.4 \%$ for $1.0 \mathrm{l} / \mathrm{min}$ and $1.5 \mathrm{l} / \mathrm{min}$, respectively.

For the three-stage module at the both stream flow rates of $1.0 \mathrm{l} / \mathrm{min}$ (black lines in Fig. $5 \mathrm{c}$ ), the measured mean permeate flux increases from $10.1 \mathrm{~kg} / \mathrm{m}^{2} \mathrm{~h}$ to $24.0 \mathrm{~kg} / \mathrm{m}^{2} \mathrm{~h}$ and the model prediction shows the increase of mean permeate flux from $9.82 \mathrm{~kg} / \mathrm{m}^{2} \mathrm{~h}$ to $25.2 \mathrm{~kg} / \mathrm{m}^{2} \mathrm{~h}$, with increasing inlet feed temperature. The predicted mean performance ratio increases from $61.8 \%$ to $79.8 \%$. With the both stream flow rates of $1.5 \mathrm{l} / \mathrm{min}$ (red lines in Fig. $5 \mathrm{c}$ ), the measured mean permeate flux increases from $11.4 \mathrm{~kg} / \mathrm{m}^{2} \mathrm{~h}$ to $29.9 \mathrm{~kg} / \mathrm{m}^{2} \mathrm{~h}$, while the predicted mean permeate flux increases from $12.8 \mathrm{~kg} / \mathrm{m}^{2} \mathrm{~h}$ to 34.0 $\mathrm{kg} / \mathrm{m}^{2} \mathrm{~h}$. The mean performance ratio also increases from $62.6 \%$ to $81.2 \%$. Here, the maximum relative deviations between measured and predicted results on the mean permeate flux are found to be $5.0 \%$ for $1.0 \mathrm{l} / \mathrm{min}$ and $13.7 \%$ for $1.5 \mathrm{l} / \mathrm{min}$. 
Based on the experimental results aforementioned, the convective heat transfer coefficient at the feed and permeate boundary layers is obtained from the procedures described in Section 3. The heat transfer coefficient obtained is correlated with spacer characteristics by the multiple linear regressions. The best fit between measured and simulated permeate fluxes is achieved with the squared correlation coefficient of 0.944 .

At the inlet feed and permeate flow rates of $1.5 \mathrm{l} / \mathrm{min}$, the model-based mean permeate flux and daily water production by varying the inlet feed temperature from $50{ }^{\circ} \mathrm{C}$ to $70{ }^{\circ} \mathrm{C}$ are compared with regard to the number of module stages, i.e., single- (black lines), two- (red lines) and three-stage (blue lines) (Fig. 6). It is noted that as the number of module stages increases from single- to two- and three-stage, on average, the mean permeate flux (solid lines) decreases by $4 \%$ and $9 \%$, whereas the daily water production (dashed lines) increases by $92 \%$ and $172 \%$, i.e., 1.92 times and 2.72 times, with an increase in the effective membrane area.

The relative good agreement between prediction results and experimental data, therefore, demonstrates that multistage module concept designed may achieve an enhancement of compactness, productivity, versatility and cost-effectiveness in the DCMD process.

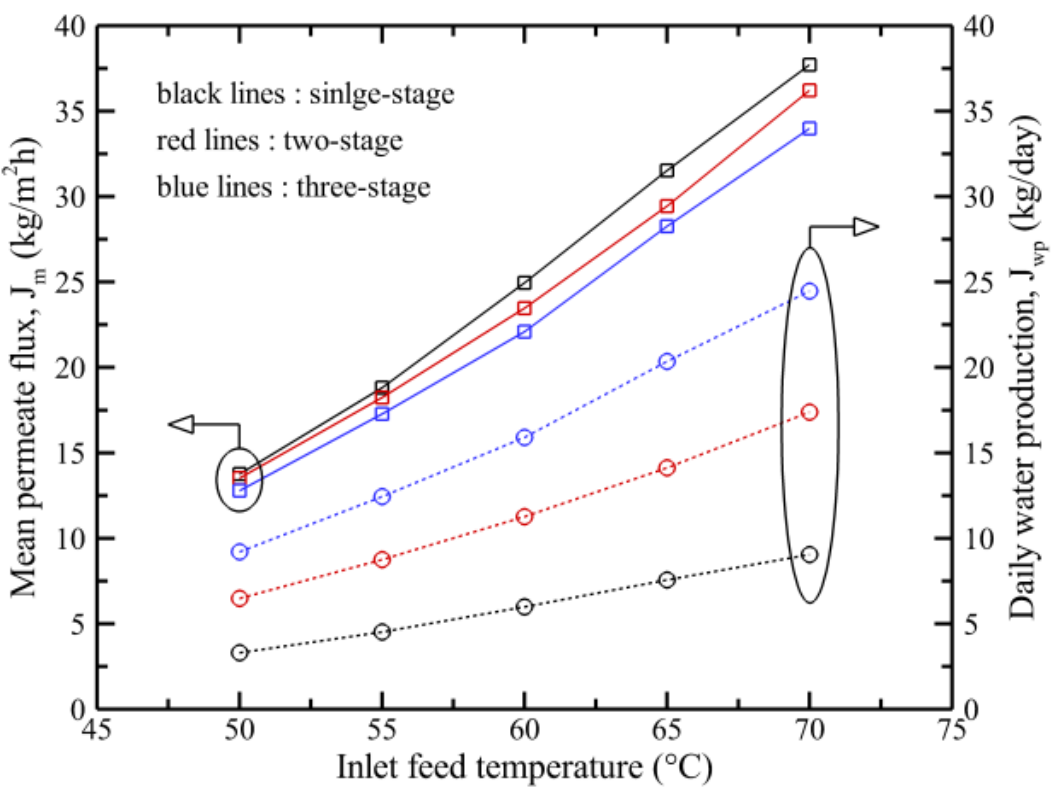

Fig. 6: Effect of inlet feed temperature on the predicted mean permeate flux and daily water production of single-, two- and three-stage module.

\section{Conclusion}

In this paper, a novel multi-stage direct contact membrane distillation (MDCMD) system is designed and its performance is examined both theoretically and experimentally. The MDCMD module with a countercurrent-flow configuration, applicable to a small scale and footprint desalination system while retaining a process performance, is first designed, and then experimental and theoretical studies are successfully performed to demonstrate the feasibility and operability of module design in terms of permeate flux, daily water production and performance ratio. Here, the theoretical model is modified to incorporate a thermal entrance effect at the inlet flow region of each stage, which has a positive influence on the DCMD performance. Model predictions and measured data for mean permeate flux are compared and shown to be in good agreement. It is shown that as the number of module stages increases from single- to two- and three-stage, the mean permeate flux decreases by $4 \%$ and $9 \%$, while the daily water production increases by 1.92 times and 2.72 times with an increase in the effective membrane area, which makes the proposed MDCMD module an attractive and energy-efficient concept for desalination application.

\section{Acknowledgements}

This research reported in this paper was supported by Basic Science Research Program through the National Research Foundation of Korea (NRF) funded by the Ministry of Education (NRF-2014R1A1A2058979) and Mid-Career Researcher 
Program through the National Research Foundation of Korea (NRF) funded by the Ministry of Science, ICT \& Future Planning (2014R1A2A2A01006899).

\section{References}

[1] R. González-Bravo, F. Nápoles-Rivera, J. M. Ponce-Ortega, M. Nyapathi, N. Elsayed, and M. M. El-Halwagi, "Synthesis of optimal thermal membrane distillation networks," AIChE J., vol. 61, pp. 448-463, 2015.

[2] J .-G. Lee and W. -S. Kim, "Numerical study on multi-stage vacuum membrane distillation with economic evaluation," Desalination, vol. 339, pp. 54-67, 2014.

[3] E. Guillén-Burrieza, J. Blanco, G. Zaragoza, D.-C. Alarcón, P. Palenzuela, M. Ibarra, and W. Gernjak, "Experimental analysis of an air gap membrane distillation solar desalination pilot system," J. Membr. Sci., vol. 379, pp. 386-396, 2011.

[4] K. Zhao, W. Heinzl, M. Wenzel, S. Büttner, F. Bollen, G. Lange, S. Heinzl, and N. Sarda, "Experimental study of the memsys vacuum-multi-effect-membrane-distillation (V-MEMD) module," Desalination, vol. 323, pp. 150-160, 2013.

[5] J. Phattaranawik, R. Jiraratananon, and A. G. Fane, "Heat transport and membrane distillation coefficients in direct contact membrane distillation," J. Membr. Sci., vol. 212, pp. 177-193, 2003.

[6] J. Welty, C. E. Wicks, G. L. Rorrer, and R. E. Wilson, Fundamentals of Momentum, Heat, and Mass Transfer. New York: John Wiley \& Sons, 2009.

[7] Y.-D. Kim, K. Thu, and S. -H. Choi, "Solar-assisted multi-stage vacuum membrane distillation system with heat recovery unit," Desalination, vol. 367, pp. 161-171, 2015.

[8] J.-G. Lee, Y.-D. Kim, S.-M. Shim, B.-G. Im, and W.-S. Kim, "Numerical study of a hybrid multi-stage vacuum membrane distillation and pressure-retarded osmosis system," Desalination, vol. 363, pp. 82-91, 2015.

[9] J. Blanco Gálvez, L. García-Rodríguez, and I. Martín-Mateos, "Seawater desalination by an innovative solar-powered membrane distillation system: the MEDESOL project," Desalination, vol. 246, pp. 567-576, 2009.

[10] M. Khayet and T. Matsuura, Membrane Distillation: Principles and Applications. Elsevier, 2011.

[11] J.-G. Lee, Y.-D. Kim, W.-S. Kim, L. Francis, G. Amy, and N. Ghaffour, "Performance modeling of direct contact membrane distillation (DCMD) seawater desalination process using a commercial composite membrane," J. Membr. Sci., vol. 478, pp. 85-95, 2015.

[12] S. Al-Sharif, M. Albeirutty, A. Cipollina, and G. Micale, "Modelling flow and heat transfer in spacer-filled membrane distillation channels using open source CFD code," Desalination, vol. 311, pp. 103-112, 2013.

[13] A. G. Fane, R. W. Schofield, and C. J. D. Fell, "The efficient use of energy in membrane distillation," Desalination, vol. 64, pp. 231-243, 1987.

[14] J. Phattaranawik, R. Jiraratananon, and A. G. Fane, "Effects of net-type spacers on heat and mass transfer in direct contact membrane distillation and comparison with ultrafiltration studies," J. Membr. Sci., vol. 217, pp. 193-206, 2003.

[15] A. R. Da Costa, A. G. Fane, and D. E. Wiley, "Spacer characterization and pressure drop modelling in spacer-filled channels for ultrafiltration," J. Membr. Sci., vol. 87, pp. 79-98, 1994.

[16] Y.-D. Kim and W.-S. Kim, "Re-evaluation and modeling of a commercial diesel oxidation catalyst," Ind. Eng. Chem. Res., vol. 48, pp. 6579-6590, 2009.

[17] Y.-D. Kim, K. Thu, N. Ghaffour, and K. C. Ng, "Performance investigation of a solar-assisted direct contact membrane distillation system," J. Membr. Sci., vol. 427, pp. 354-364, 2013.

[18] B. Li and K. K. Sirkar, "Novel membrane and device for direct contact membrane distillation-based desalination process," Ind. Eng. Chem. Res., vol. 43, pp. 5300-5309, 2004.

[19] T. Y. Cath, V. D. Adams, and A. E. Childress, "Experimental study of desalination using direct contact membrane distillation: a new approach to flux enhancement," J. Membr. Sci., vol. 228, pp. 5-16, 2004.

[20] S. Al-Obaidani, E. Curcio, F. Macedonio, G. Di Profio, H. Al-Hinai, and E. Drioli, "Potential of membrane distillation in seawater desalination: thermal efficiency, sensitivity study and cost estimation," J. Membr. Sci., vol. 323, pp. 85-98, 2008.

[21] M. S. El-Bourawi, Z. Ding, R. Ma, and M. Khayet, "A framework for better understanding membrane distillation separation process," J. Membr. Sci., vol. 285, pp. 4-29, 2006. 